\title{
Evaluating the Heterogeneous Effect of Firm Risk on Firm Value
}

\author{
Thi Hong Nhung Nguyen 1 1* \\ ${ }^{1}$ Alfred Lerner College of Business \& Economics, University of Delaware, USA \\ * Corresponding author: nhungng@udel.edu
}

Article History

Received 2020-08-05

Revised 2020-08-30

Accepted 2020-08-31

Published 2020-09-04

\section{Keywords}

Causal inference

Firm risk

Firm value

Heterogeneous effect

\section{How to cite?}

Nguyen, T. H. N. (2020). Evaluating the

Heterogeneous Effect of Firm Risk on

Firm Value. SEISENSE Journal of

Management, 3(5), 24-32. doi:

$10.33215 /$ sjom.v3i5.430

\section{Abstract}

Purpose- This paper aims to investigate the effect of firm risk on the firm value to see how the firm value is changing when the risk level is changed. Our result indicates that a higher level of risk can reduce firm value.

Design/Methodology- We apply a Bayesian causal technique for a sample data set of US public firms. The causal approach helps us to focus on the reliable and unbiased results instead of the association-based findings.

Findings- The results show a negative effect of risk on the firms' value for the sample data. However, we investigate the potential effect of the risk across the distribution of the firm value. We witness the more substantial effect of risk on firms with a higher value.

Practical Implications- Helps firms to evaluate their risk and its effect, so they can adjust their decisions and take actions to reduce the undesired effects of firm risk.

\section{(cc) BY}




\section{Introduction}

The firm value and firm risk have been widely investigated in the finance literature. It is so essential for each firm to monitor its value and investigate the different factors that can influence the firm value. Firm risk can have different impacts on various aspects of the firms. These effects have been studied in various contexts and resulted in two groups of research. The leading group of studies supports the risk-return tradeoff theory, which is also known as the fundamental theory in finance literature. Based on this theory, there is a positive association between the risk and return, meaning that the higher return should be expected to take higher risks. This approach is more vital for the stock portfolio than for the firms. However, another group of related studies revealed a negative correlation between these two variables. Bowman (1980)found the negative association between the risk and return, which has been named Bowman's paradox. After Bowman, a considerable amount of studies published the same results and supported the paradox. Related research showed that taking a risk may result in a lower return instead of a premium. This could happen because of the poor performance of decision-makers to impact the firms negatively in terms of risk and return at the same time.

There are so many studies that examined the relationship between the risk and return for firms. The related literature provides the mixed finding of positive and negative effects (Bowman, 1980; Chari, David, Duru, \& Zhao, 2019; Faraji, 2020; Faraji \& Fleischhacker, 2020; Yang, Riepe, Moser, Pull, \& Terjesen, 2019). Therefore, the effect of risk on firm value or performance is not completely clear. A tiny fraction of the related research focuses on finding the more concrete results by deploying the causal approach (Faraji, 2020; Faraji \& Fleischhacker, 2020). Based on this group of research, the reason for mixed findings is the correlation-based models, which are unable to tease out the accurate and stable magnitude of the effects. The causal approach can extract the unbiased effect by applying causal models (Hernán \& Robins, 2010). This study is motivated based on the approach that has been used by (Faraji \& Fleischhacker, 2020). They showed that when the main question is not correlation-based, then Bayesian causal models can provide reliable and concrete results for observational studies. They are among the first researchers that consider the Bayesian approach for causal model to remove the spurious associations for observational financial data. We are considering Bayesian causal models for financial data instead of frequentist association-based models to provide more reliable and less biased results; all these goals have been considered and applied by (Faraji \& Fleischhacker, 2020). They provide a comprehensive study to overcome the limitation of the related studies. Following their approach, we extend this work with causal inference to examine the effect of risk on firm value.

The rest of this paper includes the following sections, the next section discusses a literature review about firm risk and firm value, following with a review of the causal inference for observational studies. Then the research method section, the empirical results, are provided with a description of the data. The last section is about the conclusion and limitations of the present paper.

\section{Literature Review}

The relationship between firm risk with the performance or firm value has been widely studied in financial literature. The risk-adjusted return approach is based on the positive correlation between risk and return. Applying the risk-adjusted return helps to examine the amount of risk that should be taken to gain the desired level of return. Different measures such as the Sharpe Ratio, Appraisal Ratio, and Treynor Ratio investigate how the risk and return change together (Faraji, 2020; Lee \& Li, 2012; Sharpe, 1966). Also, the positive relationship has been found between risk and expected return, which means that managers should choose risk investment only if it can maximize the stakeholder wealth (Barberis, Huang, \& Santos, 2001; Chari et al., 2019; Merton, 1987). 
In contrast, Bowman's risk-return paradox shows the negative relationship between risk and return. Different factors, such as poor management or personal benefits, may lead to making decisions that increase the risk and reduce the value for firms (Bowman, 1980). Indeed, managers impose the risk-discount by taking a higher risk for the same or even lower level of return. According to Ang, Hodrick, Xing, and Zhang (2006)) risk and firm return have a negative association. One way to explain such this paradox is through the agency problem (Chari et al., 2019). Risk-averse managers only take higher risks if they can gain a higher return. However, the empirical results show that career concerns may push managers to make high risk and value reducing decisions. Also, the solution to avoid such decisions is to have more robust corporate governance (Chari et al., 2019). Also, another group of research supports Bowman's paradox differently by providing empirical results, wherein it shows increasing return and reducing risk (Yang et al., 2019). This effect can be seen in firms with related business segments; however, in firms with unrelated business segments, it is more likely to observe the positive association between risk and return (Bettis \& Hall, 1982). Indeed, the synergy among the different segments can help the firms to reduce their cost and risk. Economic of scale, shared resources, managerial skills, and information are among the key factors that can empower the firms (Yang et al., 2019). The relationship between risk and return can be explained well in the context of diversification (Faraji \& Fleischhacker, 2020).

Many studies tried to investigate the potential role of other firms' aspects in the relationship between risk and return. As mentioned before, the corporate governance variables may play a mediating role and result in a suppressed mediating effect (Chang, Yu, \& Hung, 2015). Also, the role of various financial variables can be examined by applying different measures to evaluate firm risk and value. They are using cash flow volatility as a risk measure that shows a negative association between firm value and risk (Rountree, Weston, \& Allayannis, 2008). Another research reports the negative association between cash flow volatility and firm value, which is measured by Tobin's Q (Chi \& Su, 2017). Also, it has been reported that this association depends on the firm investment opportunities, firm size, and the correlation among business segments (Chi \& Su, 2017; Pástor \& Pietro, 2003) leads to a negative association between firm valuation and firm's profitability when the firm age increases. Shin and Stulz (2000) provided the different relationships between firm value using Tobin's Q with systematic and unsystematic risk. They suggested the firm value increases with the systematic risk but decreased with the unsystematic risk. Also, the effect on the female board on Norwegian firms' risk and performance has been studied in a causal context, by using Tobin's $\mathrm{Q}$ and real risk as to the measures for firm value and risk (Yang et al., 2019). In this study, the difference-in-difference approach has been used to find the unbiased and negative effect of female directors on firm performance and risk. In another study which focuses on stability of the firm's risk-return association across the market trends (Gupta \& Pathak, 2018). Their sample data includes firms form developed and emerging countries. The results showed that the paradoxical and positive relationship between risk and return, however, they found the firms in emerging countries riskier than the developed countries.

Following the related literature, we use Tobin's Q to measure the firm value in this paper (e.g., (Chi \& Su, 2017; Shin \& Stulz; Yang et al., 2019). Which is the market value of equity plus debt divided by assets? Also, we measure the firm risk with absolute risk, which is the annual standard deviation of firms' daily stock return (Lee \& Li, 2012; Yang et al., 2019). This is a well-established measurement of total firm risk and can be estimated as the sum of the squared daily log returns when the mean value of the daily log returns is subtracted. This risk measure provides a complete picture by capturing the full risk for the firms as well as the investors (Yang et al., 2019).

\section{Causal Inference for Observational Study}

By reviewing the related research, the mixed results are based on the association. However, the results based on the correlation can be biased for observational data (Faraji, 2020). We deploy a causal inference approach to find the more accurate effect of the variables. It is required to apply a causal model instead of association-based 
models to remove the undesired association, such as the confounding effect. The difficulty of causal inference is related to the data limitation, which refers to the missing potential outcomes in causal studies. In observational studies, only one outcome is observed for each individual, and the others are not observed. However, with a binary exposure, both potential outcomes are required to find the effect of exposure on the outcome of interest. To overcome this limitation, causal models are helpful in finding the average effect of the variables by considering the effect across the population instead of individuals (Rubin, 2005).

In causal inference, valid results depend on holding the causal assumptions. Without these assumptions, we are not able to interpret the results in a causal context. These assumptions are Positivity, Consistency, and exchangeability (Hernán \& Robins, 2010). Positivity refers to having a positive probability of receiving all the exposure levels for individuals. Defining an apparent intervention lead to holding the consistency assumption. The last assumption or exchangeability means that the information about the intervention cannot help to estimate the outcome variable. Indeed, for intervention levels, the intervention and outcomes are independent (Hernán \& Robins, 2010).

Following Hernán and Robins (2010), we assume the outcome as $Y$, intervention as $A$, and other variables that can result in confounding bias as $L$. Then the potential outcomes for each individual $i$ in the sample population are $Y_{i}^{1}$ and $Y_{i}^{0}$, which represent the potential outcome with assigned intervention and with no intervention assigned respectively. The individual effect in the causal context would be $Y_{i}^{1}-Y_{i}^{0}$, However, as mentioned before only one of these outcomes is observed. Consequently, finding the effect size at individual level or $Y_{i}^{1}-$ $Y_{i}^{0}$ is impossible. Finding the average effect for the population can handle this problem (Rubin, 2005).

The average effect can be calculated based on equation (1):

$$
E\left(Y_{i}^{1}-Y_{i}^{0}\right)=E\left(Y_{i}^{1}\right)-E\left(Y_{i}^{0}\right)
$$

By estimating these values, we can find the average effect as:

$$
\mathrm{E}\left(\mathrm{Y}_{\mathrm{i}} \mid \mathrm{A}=1\right)-\mathrm{E}\left(\mathrm{Y}_{\mathrm{i}} \mid \mathrm{A}=0\right)
$$

If there is any confounding bias, then we should find the average effect given the confounders variables as:

$$
\text { Average Effect }=E\left(Y_{i} \mid A=1, L\right)-E\left(Y_{i} \mid A=0, L\right)
$$

Following Faraji and Fleischhacker (2020), we use a causal model to examine the presence of a causal relationship between risk and firm value.

\section{Research Method and Data}

\section{Sample Data}

Different financial variables are considered as control variables in associational studies. In the current paper, we look for the confounding variables to remove their associated bias. We consider the age, size, growth opportunity, and leverage as confounders. The causal model helps to remove the confounding bias to drive the more accurate effect of the risk on firm value. As mentioned before, the continuous outcome is a firm value measured by Tobin's Q, which is the market-based measure. Also, the intervention or risk here is measured as the annual standard deviation of firm stock return, which can be calculated as the variance of the sum of the squared of subtracting the mean value of daily $\log$ return form the daily log returns. Many studies consider a binary or multi-level measure for risk, such as the famous Altman Z-Score (Altman, 1968). Faraji (2020) consider the distress risk as a binary variable in a causal study. Following the related literature, we assume risk as a binary variable with a high and low level of risk for firms. Indeed, we consider the firms with lower risk 
than the median risk value as firms with low risk and firms with a higher risk than the median value as high-risk firms. As a result, we suggest having a binary exposure to examine the effect of risk. The data are extracted from CRSP and Compustat data sources. The data covers 2018 for around 2800 US public firms. The next table provides a summary of descriptive statistics for the variables of this study.

Table 1 - Descriptive statistics of the variables

\begin{tabular}{llll}
\hline Variable & Mean & Sd & Median \\
\hline Age & 19.05 & 15.61 & 18.00 \\
Total Assets & 10147.2 & 37087.35 & 1198.6 \\
Total Liabilities & 6401.5 & 21985.53 & 589.1 \\
Debt Ratio & 0.5681 & 0.765 & 0.5402 \\
Size & 6.515 & 1.91 & 6.987 \\
Growth Opportunity & 0.0742 & 0.39 & 0.00 \\
Tobin's Q & 1.074 & 5.29 & 0.688 \\
Risk & 0.0264 & 0.018 & 0.01987 \\
\hline
\end{tabular}

\section{Bayesian Statistical Model}

Different causal models can help us to find the average effect for the population with observational data. In this study, we use g-formula to find the average effect. We provide a quick summary of the g-formula here, but we refer the reader to Hernán and Robins (2010) and Faraji and Fleischhacker (2020) for more details. Under the three assumptions of consistency, positivity, and exchangeability, the g-formula helps to estimate the missing potential outcomes to sample the counterfactual means. Different steps are required in this model to be taken to estimate the parameter of interest or average effect. First, the parameters' estimations should be obtained to find $E\left(Y^{1}\right)$ and $E\left(Y^{0}\right)$ by the following equation:

$$
\widehat{\mathrm{E}}\left(\mathrm{Y}^{\mathrm{a}}\right)=\sum_{\mathrm{l}} \widehat{\mathrm{E}}[\mathrm{Y} \mid \mathrm{A}=\mathrm{a}, \mathrm{L}=\mathrm{l}] \operatorname{Pr}[\mathrm{L}=1]
$$

Where a represents a binary exposure (Risk), $\mathrm{Y}$ is the potential outcome (Firm value), and L can be a single or a vector of potential confounders. Then the average effect is calculated by:

$$
\text { Average Effect }=\widehat{\mathrm{E}}\left(\tilde{\mathrm{y}}^{\mathrm{a}=1}\right)-\widehat{\mathrm{E}}\left(\tilde{\mathrm{y}}^{\mathrm{a}=0}\right)
$$

Here, we use a Bayesian version of the causal technique to drive the sample of the parameters to estimate the counterfactual means. We consider a normal distribution for the firm value as a continuous outcome with risk as a binary intervention.

$$
\begin{gathered}
\text { Firm Value }(\mathrm{Y}) \sim \mathrm{F}\left(\operatorname{Risk}(\mathrm{A}) \text {, Size }\left(\mathrm{L}_{1}\right), \text { Age }\left(\mathrm{L}_{2}\right) \text {, Debt Ratio }\left(\mathrm{L}_{3}\right) \text {, Growth Opportunity }\left(\mathrm{L}_{4}\right)\right) \\
\qquad \begin{array}{c}
\text { Firm Value }(Y) \sim \operatorname{Normal}(\mu, \sigma) \\
\mu=\alpha_{0}+\alpha_{a} A+\alpha_{1} L_{1}+\alpha_{2} L_{2}+\alpha_{3} L_{3}+\alpha_{4} L_{4}
\end{array}
\end{gathered}
$$

We use weakly informative prior information for the parameters:

$$
\begin{gathered}
\alpha_{a}, \alpha_{1}, \ldots, \alpha_{4} \sim \text { cauchy }(0,2.5) \\
\alpha_{0} \sim \text { cauchy }(0,10) \\
\sigma \sim \text { cauchy }(0,1)
\end{gathered}
$$

Then the average treatment effect of diversification on the outcome is the difference between the mean of these two groups of high risk and low-risk potential outcomes.

$$
\tilde{y}^{a=1} \sim \operatorname{Normal}\left(\widehat{\alpha_{0}}+\widehat{\alpha_{a}} A+\widehat{\alpha_{1}} L_{1}+\widehat{\alpha_{2}} L_{2}+\widehat{\alpha_{3}} L_{3}+\widehat{\alpha_{4}} L_{4}, \hat{\sigma}\right)
$$




$$
\tilde{y}^{a=0} \sim \operatorname{Normal}\left(\widehat{\beta_{0}}+\widehat{\alpha_{1}} L_{1}+\widehat{\alpha_{2}} L_{2}+\widehat{\alpha_{3}} L_{3}+\widehat{\alpha_{4}} L_{4}, \widehat{\sigma}\right)
$$

\section{Results}

The sample draws from the hyperparameters are the output of our statistical models, then we should find the posterior predictive of the counterfactual outcomes by using them. The next table gives a summary of the hyperparameters estimation.

Table 2 - Summary of hyperparameter estimation

\begin{tabular}{cccccccc}
\hline Parameter & mean & sd & $\mathbf{2 . 5 \%}$ & $\mathbf{2 5 \%}$ & $\mathbf{5 0 \%}$ & $\mathbf{7 5 \%}$ & $\mathbf{9 7 . 5 \%}$ \\
\hline $\boldsymbol{\alpha}_{\mathbf{1}}$ & 0.66 & 10.40 & -19.36 & -6.26 & 0.51 & 7.68 & 21.37 \\
$\boldsymbol{\alpha}_{\mathbf{2}}$ & -0.65 & 0.05 & -0.75 & -0.69 & -0.65 & -0.61 & -0.55 \\
$\boldsymbol{\alpha}_{\mathbf{3}}$ & 0.11 & 0.05 & 0.02 & 0.07 & 0.11 & 0.14 & 0.20 \\
$\boldsymbol{\alpha}_{\mathbf{4}}$ & -0.01 & 0.05 & -0.11 & -0.05 & -0.01 & 0.02 & 0.08 \\
\hline
\end{tabular}

Then the average effect can be determined using equation (5). The following figure illustrates the distribution of the average effect for the exposure.

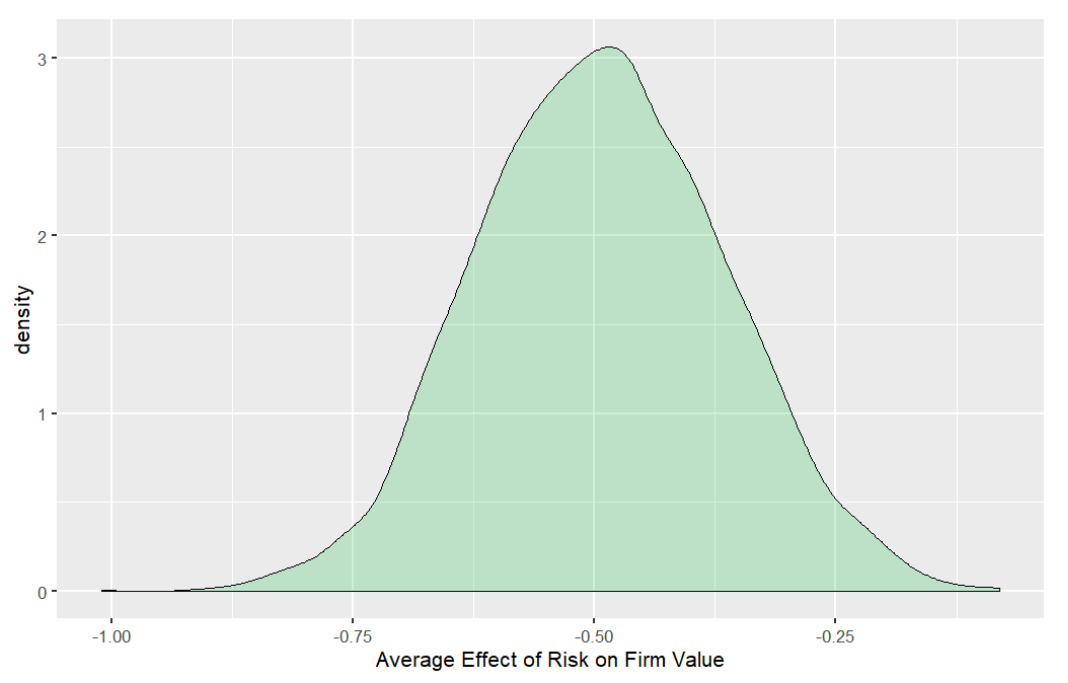

Figure 1 - Average Effect of Risk on Firm Value

According to the figure (1), the negative values across the distribution of effect shows the negative effect of risk on the firm value, which indicates that the firms with higher risk experience the lower value, while firms with lower risk having higher firm value. This means that risk is negatively associated with firm value but after removing the selection bias, confounding bias, and mediating effects, there is still a negative causal effect between them. These results support the Bowman's paradox with a causal approach.

We examined the effect of risk on the firms' value by considering low-risk firms and high-risk firms. Providing an average effect can be helpful when the effect is similar across the population. However, instead of summarizing all information in just one number, we can consider the effect across the outcome distribution. This approach can provide more information about the potential variation of effect distribution. The quantile treatment effect (QTE) shows the heterogeneous effect. The quantile approach investigates the effect for different quantiles and tails instead of the mean value (Bitler, Gelbach, \& Hoynes, 2006; Koenker, 2005). This approach is useful when the effect in different quantiles are not similar to the average effect. As the average effect is more based on the parametric regression models, QTE deploys quantile regressions to find the effects. 
Indeed, QTE finds the difference between the distributions of potential outcomes based on the inverse cumulative distribution functions for the quantiles (Koenker, 2005). The QTE can be defined as follows in a simple way:

$$
\mathrm{QTE}_{\mathrm{q}}=\mathrm{F}_{\mathrm{y}^{\mathrm{a}}=0}^{-1}(\mathrm{q})-\mathrm{F}_{\mathrm{y}^{\mathrm{a}=0}}^{-1}(\mathrm{q})
$$

As the second research question, we investigate the potential heterogeneous effect of the risk on firm value. The next table shows the distribution of effect.

Table 3 - QTE of Risk on Firm Value

\begin{tabular}{ccc}
\hline Quantile & QTE & Std. Error \\
\hline $\mathbf{0 . 0 5}$ & -0.018 & 0.000 \\
$\mathbf{0 . 1 0}$ & -0.017 & 0.000 \\
$\mathbf{0 . 1 5}$ & -0.006 & 0.000 \\
$\mathbf{0 . 2 0}$ & -0.017 & 0.000 \\
$\mathbf{0 . 2 5}$ & -0.011 & 0.000 \\
$\mathbf{0 . 3 0}$ & -0.012 & 0.000 \\
$\mathbf{0 . 3 5}$ & -0.006 & 0.000 \\
$\mathbf{0 . 4 0}$ & -0.001 & 0.000 \\
$\mathbf{0 . 4 5}$ & -0.010 & 0.000 \\
$\mathbf{0 . 5 0}$ & -0.006 & 0.000 \\
$\mathbf{0 . 5 5}$ & -0.011 & 0.000 \\
$\mathbf{0 . 6 0}$ & -0.012 & 0.000 \\
$\mathbf{0 . 6 5}$ & -0.011 & 0.000 \\
$\mathbf{0 . 7 0}$ & -0.044 & 0.000 \\
$\mathbf{0 . 7 5}$ & -0.179 & 0.000 \\
$\mathbf{0 . 8 0}$ & -0.811 & 0.000 \\
$\mathbf{0 . 8 5}$ & -0.583 & 0.000 \\
$\mathbf{0 . 9 0}$ & -0.934 & 0.000 \\
$\mathbf{0 . 9 5}$ & -1.376 & 0.000 \\
\hline
\end{tabular}

The results for the quantile effect are consistent with the distribution of average effect. Table 3 shows the negative effect on all quantiles, which means that higher risk leads to a lower value for firms. However, the heterogeneous effect would get clear in figure 2.

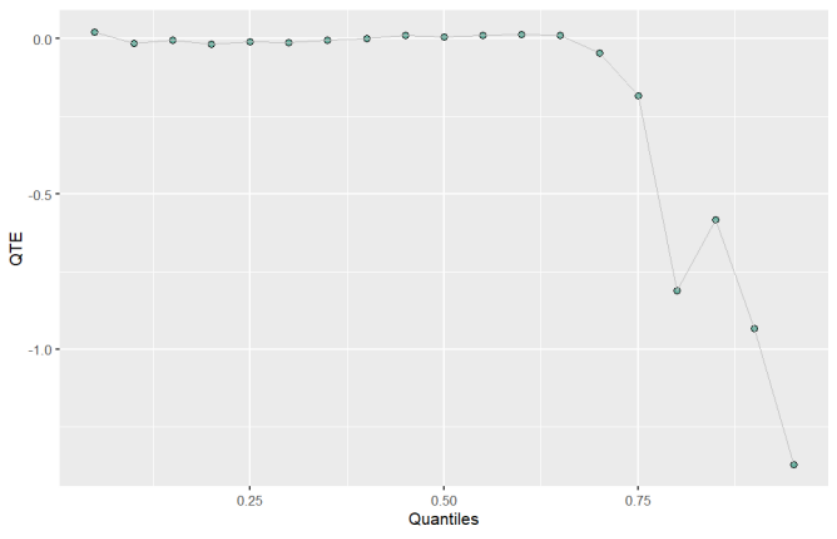

Figure 2 - QTE of Risk on Firm Value

According to the figure (2), while the effect of risk on firm value is almost in the same range from $5 \%$ quantile to $70 \%$ quantile, it decreases dramatically for the higher quantiles. This figure illustrates the heterogeneous effect sizes. This shows that only considering the average effect can provide a limited picture of the results. 
Extending the study with quantile analysis in a simple framework can enable decision-makers and other researchers to examine the detailed information about the effect of risk on the firm value and adjust their decisions accordingly.

\section{Conclusion:}

In this study, we examine the causal effect of firm risk on the firm value measured by Tobin's Q for a sample of US public firms. We start with the average effect to see how the value of a risky firm can be impacted by the risk compared with fewer risk firms. The results show that risky high firms suffer from lower firm value. However, firms that experience a low level of total risk are experiencing a less negative effect on their values. This result supports the Bowman's paradox in some way as having a negative relationship between the firm risk and value. Also, we consider the potential heterogeneity for this effect across the distribution of firm values. The results provide more details about the heterogynous effect of the fire risk. It is so interesting to see that for firms at higher quantiles experience a more substantial effect than the firm in lower quantiles. Also, there are some limitations to this study. We suggest investigating more confounders and cover more years in the study for future studies.

Funding: There is no funding source for this paper.

Conflicts of Interest: The corresponding author states that there is no conflict of interest.

\section{References}

Altman, E. I. (1968). Financial ratios, discriminant analysis and the prediction of corporate bankruptcy. The journal of finance, 23(4), 589-609.

Ang, A., Hodrick, R. J., Xing, Y., \& Zhang, X. (2006). The cross-section of volatility and expected returns. The Journal of Finance, 61(1), 259-299.

Barberis, N., Huang, M., \& Santos, T. (2001). Prospect theory and asset prices. The quarterly journal of economics, 116(1), 1-53.

Bettis, R. A., \& Hall, W. K. (1982). Diversification strategy, accounting determined risk, and accounting determined return. Academy of Management journal, 25(2), 254-264.

Bitler, M. P., Gelbach, J. B., \& Hoynes, H. W. (2006). What mean impacts miss: Distributional effects of welfare reform experiments. American Economic Review, 96(4), 988-1012.

Bowman, E. H. (1980). A risk/return paradox for strategic management.

Chang, C.-S., Yu, S.-W., \& Hung, C.-H. (2015). Firm risk and performance: the role of corporate governance. Review of Managerial Science, 9(1), 141-173.

Chari, M. D., David, P., Duru, A., \& Zhao, Y. (2019). Bowman's risk-return paradox: An agency theory perspective. Journal of Business Research, 95, 357-375.

Chi, J. D., \& Su, X. (2017). The dynamics of performance volatility and firm valuation. Journal of Financial and Quantitative Analysis, 52(1), 111-142.

Faraji, Z. (2020). The Causal Analysis of Financial Distress Risk and Performance. American International Journal of Business Management, 3(5), 5.

Faraji, Z., \& Fleischhacker, A. (2020). Overstatement of firm diversification effect on bankruptcy risk reduction. International Journal of Applied Decision Sciences, 13(3), 267-285.

Gupta, R. D., \& Pathak, R. (2018). Firm's Risk-Return Association Facets and Prospect Theory FindingsAn Emerging versus Developed Country Context. Risks, 6(4), 143.

Hernán, M. A., \& Robins, J. M. (2010). Causal inference: CRC Boca Raton, FL;.

Koenker. (2005). Quantile Regression (Econometric Society Monographs; No. 38): Cambridge university press.

Lee, B. S., \& Li, M.-Y. L. (2012). Diversification and risk-adjusted performance: A quantile regression approach. Journal of Banking \& Finance, 36(7), 2157-2173. 
Merton, R. C. (1987). A simple model of capital market equilibrium with incomplete information.

Pástor, L., \& Pietro, V. (2003). Stock valuation and learning about profitability. The Journal of Finance, 58(5), 1749-1789.

Rountree, B., Weston, J. P., \& Allayannis, G. (2008). Do investors value smooth performance? Journal of Financial Economics, 90(3), 237-251.

Rubin, D. B. (2005). Causal inference using potential outcomes: Design, modeling, decisions. Journal of the American Statistical Association, 100(469), 322-331.

Sharpe, W. F. (1966). Mutual fund performance. The Journal of business, 39(1), 119-138.

Shin, H.-H., \& Stulz, R. M. (2000). Firm value, risk, and growth opportunities: National bureau of economic research.

Yang, P., Riepe, J., Moser, K., Pull, K., \& Terjesen, S. (2019). Women directors, firm performance, and firm risk: A causal perspective. The Leadership Quarterly, 30(5), 101297. 